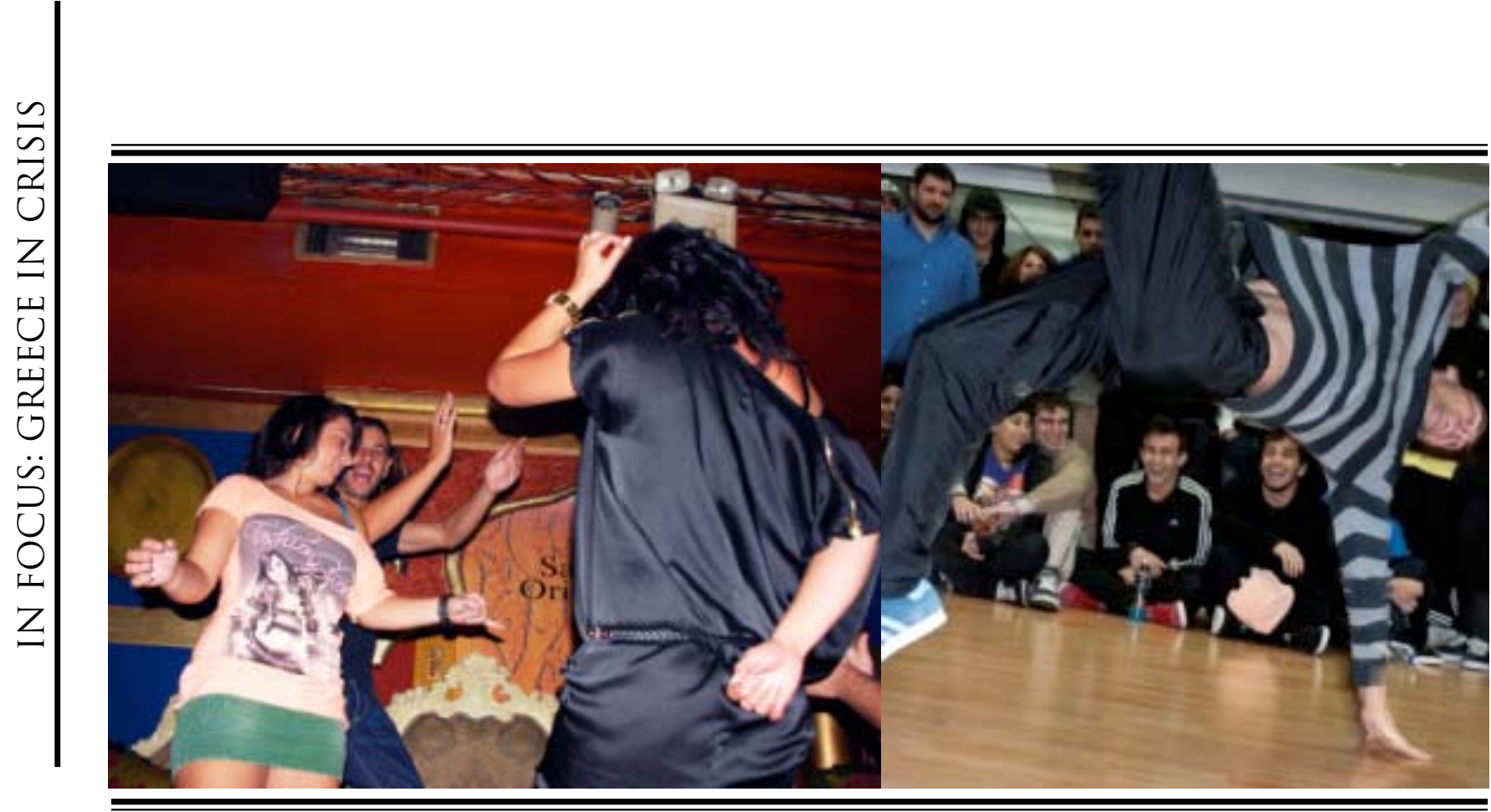

\title{
FROM STREET DANCES AND 'BREAKING' TO NIGHT CLUBBING: POPULAR ENTERTAINMENT AS CULTURAL AND SYMBOLIC CAPITAL IN CONTEMPORARY ATHENS
}

\section{TEXT BY NATALIA KOUTSOUGERA \\ PHOTOGRAPHY BY TATIANA KOUTSOUGERA}

\begin{abstract}
This paper is an anthropological portrayal of two cultural forms of popular entertainment, with a central emphasis on their dance practices: hip hop dance styles and night clubbing. Their main components are discussed in relation to emotions, materials and regulatory language and how these surround the sense of authenticity of the self. Breakdance, street dances of the Athens hip hop scene and night clubbing practices in the western suburbs of Athens unravel in a descriptive manner in order to illuminate their interwoven elements in terms of authenticity and the permutations of popular entertainment. The cultural and symbolic agendas of the subjectivities and collectivities engaged in these popular cultural forms unveil, along with the ways global and local discourses intersect, to produce a territory for identity formation. By highlighting the key aspects of popular entertainment in contemporary Greece, the aim of this article is to contribute to the anthropological study of popular culture by pointing out its role in the processes of shaping and performing subjectivity and in the production of authenticity.
\end{abstract}

\section{TWO POPULAR DANCE CULTURES BOTH DISTINCT AND INTERCONNECTED}

$\mathrm{T}$ his article explores two different but interrelated ethnographic examples in Greece, street dances and breakdance of the Athens hip-hop scene, and night clubbing practices in the western suburbs of Athens. These two music and dance cultures differ significantly as to the musical forms, styles and practices used by young people who belong to them. However, they both share something in common: they are widely considered as popular forms of entertainment. Popular entertainment is a controversial and elusive category which is connected to popular aesthetics and taste, employed by individuals and collectivities as 'cul- 
tural' and 'symbolic capital' (Bourdieu 1979).

As Sarah Thornton comments on Bourdieu's definition of cultural capital 'it is the linchpin of a system of distinction in which cultural hierarchies correspond to social ones and people's tastes are predominately a marker of class' (1996: 10). In this respect, the discourses of these two music and dance cultures may function as ideologies of taste and style which fulfill the specific cultural and symbolic agendas of their participants, while at times these apparently contrasting discourses appear to escape their specificity by intersecting, fusing or exchanging elements. Accordingly, one of the claims of this paper is that different forms of popular culture consist of flows of meanings, discourses, strategies and practices which correspond to each other, constantly debating their boundaries and sometimes cooperating to construct a concrete basis for expressions of the popular to thrive.

The street dances and all breakdance-related data in this article are based on anthropological fieldwork carried out between May 2010 and October 2011 for the co-production of a ten minute video on street dance styles of the hip hop scene in Greece and a 40 minute ethnographic film on 'breaking' (Born to Break). Interviews were conducted with teachers and student-level dancers comprising members of crews, focusing mainly on two Athens-based 'breaking' crews, well-known at the time: Lucky Dice and Dead Prezz. The research on night clubbing in the western suburbs of Athens is a part of the author's forthcoming doctoral thesis about night clubbing practices and young people in the working class suburb of Peristeri, West Athens.

Performers' identities were created and reshaped through the mobilisation and appropriation of imported materials from the wider international breakdance culture, fusing them with local meanings and experiences concerning team spirit and aspects of authenticity. In a similar vein, as far as the night clubbing practices that belong to the sphere of the Greek mainstream are concerned, it was challenging to explore how authenticity blends and intersects with local and indigenous notions of 'the popular'. One aspect of the popular, laiko, is associated with specific cultural meanings as well as personal characteristics, class idioms and connotations in different contexts and among different site-specific night clubbing cultures. As described later in our discussion, a laiko person attains certain attributes connected to one's 'true' and authentic identity.

In view of the above, these two distinct cultures are paradoxically interconnected through key ideas, values and a common ground in the search for authenticity - but without conveying an ideological identification - and at times through phenomenological similarities (music/dance/style). Thus, with the presentation and juxtaposition of both street dances and night clubbing, this paper is first and foremost an anthropological illustration of the main components of two popular dance cultures in present day Athens. This paper also attempts to demonstrate that as different as those practices might seem at first sight, they still share common ties, characteristics and attributes of critical significance. These commonalities concern affective qualities, language, goals and ideas which place these two cultures in the realm of the popular, with the latter seen as a fluid, broad category and discourse as well as a culturally specific embodied knowledge.

\section{HIP HOP CULTURE}

Hip hop is a culturally mobile, 'glocal' form, appropriated by different groups of people in cities and regions around the world. It is part of an Afro-diasporic culture attempting to negotiate the experiences of marginalization (within the context of African/Caribbean history, identity and community), to replicate and re-imagine the experiences of urban life and symbolically appropriate urban space through sampling, attitude, dance, style and sound effects (Rose 1994). Hip hop music arrived in Greece in the middle of the 1980s with the formation of a music group called FF.C (Fortified Concept). It was promoted through films such as Breakdance and Wild Style, while music groups like Public Enemy informed a young audience and triggered the emergence of many Greek hip hop groups like Terror $X$ Crew and Active Member. The latter is a cornerstone in the history of Greek hip hop, creating a special hip hop blend called Low Bap. Other, more mainstream bands were formed in the 1990s, 
such as Goin'through and Imiskoubria. Nowadays hip hop is a massive cultural phenomenon in Greece, growing rapidly in different forms, while its main elements - rapping, graffiti, djing and breaking - are used in various contexts, reflecting heterogeneous ideas and lifestyles.

\section{STREET DANCE STYLES}

Street dances of the hip hop scene, such as 'popping', 'locking', 'krumping', 'new style' and 'breaking' or 'bboying' - broadly known as breakdance $^{1}$ - have become very popular over the last few years in Greece. Their popularity was due to youth's widespread involvement in hip hop and their engagement in street styles and street art (graffiti). This emerged alongside the promotion of hip hop through dance TV shows and contests as well as proliferation of music and music videos in the media. The rapid pace of urbanization and constant flows of migration, framed by the emerging social and economic crisis in Greece, reinforced this preoccupation of young people with hip hop and street culture.

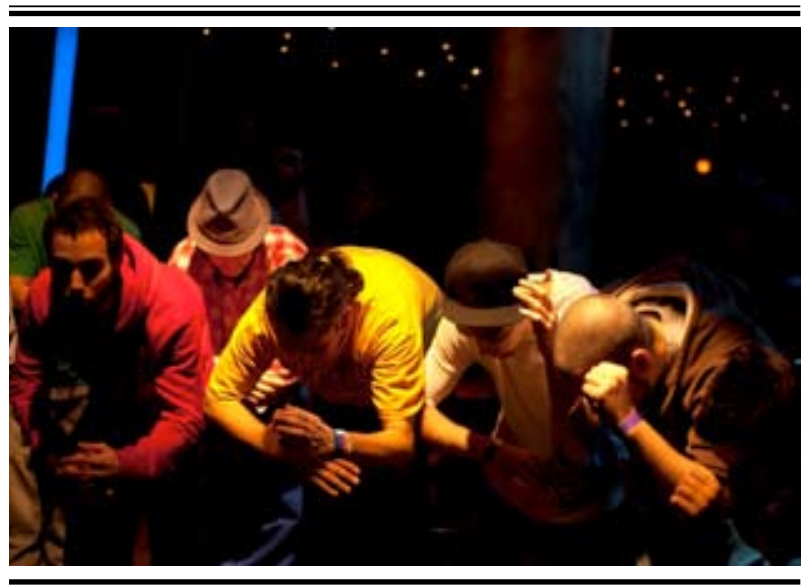

Apart from their apparent entertaining and sporty character, these dances also constitute a 'serious' activity. It becomes part of everyday life, revolving around clothing and material culture, team spirit, friendships and flirting, competition and 'battling'. Above all, it is the aspect of authenticity that emerges as the essential quality and discourse of hip hop culture. 'Keeping hip hop real' and 'keeping hip hop right' (Chang 2007: xii) directly invoke a uniqueness that has to be preserved by 'real' and 'right' individuals. These young individuals (the average age is 25) of various origins occupy several public and pri- vate spaces in the city of Athens: squares, buildings, dance schools and training places. Street dancers participate in local and international dance contests and festivals. Their dancing idiosyncrasies depend upon the kind of dance they are engaged with. For example, 'poppers' who perform robotic mimicry are comical and grotesque compared to breakers, who use a much more aggressive dance language. Theatricality is significant to all these types of street dance, while style is also a defining element among dancers.

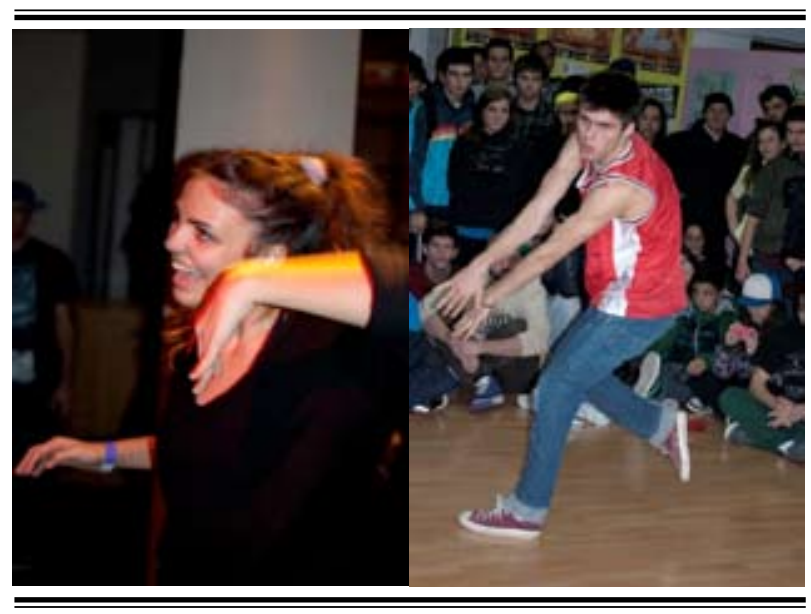

\section{'BREAKING'}

'Breaking' is one of the most popular street dances in Greece. The majority of breakers believe that it is the most authentic and pure dance form within hip hop. It first appeared in early 1975 in the Bronx, adopted by street gangs and developed as one of the four elements of hip hop: graffiti, DJ-ing, MC-ing and breaking. Prior to 1994, young dancers were practicing and experimenting with acrobatics in several places in Greece, but these were independent from hip hop culture. It was Chris Stammis, a member of the famous Swedish team Throw Down, who arrived in the country in 1994 to teach and impart his knowledge on breaking as part of hip hop culture. In 1998 he danced in a Terror X Crew music video and one year later he started teaching. He also organised the first breakdance contest: 'The battle of the year', held in 2001. Later on, various groups were created, contests and 'battles' were organized and 'breaking' gradually evolved from a street-only dance to a widespread activity in schools as well.

The first breakers in Greece were second gen- 
eration immigrants or repatriated Greek immigrants. During the 1990s, Greece witnessed a heavy influx of Albanians and immigrants from other former Socialist countries. Moreover, in the 2000s a significant number of refugees and illegal immigrants from the Middle East and Africa entered the country. Nowadays, a lot of young people involved in breakdancing are of non-Greek descent and through 'breaking' they seek to blend into Greek culture. For them, as well as for Greek dancers, breaking and hip hop are ways of embracing other cultures as well as focusing upon the common elements that bond them together by following the hip hop principles of peace, love, unity and fun as sources of survival and pleasure. Some breakers claim that its team spirit is 'a unifying element' between different cultures, but also within individual communities, providing a sense of belonging and a way of negotiating their cultural identity. In the case of the Dead Prezz crew, for instance, which is an all-Albanian group from the region of Aspropirgos (West Attica), breakdancing functioned as a bond between members of the same ethnicity and mediated between their past and a present identity.

For the purposes of the film, two crews were interviewed and studied closely, Lucky Dice (mainly Greek) and Dead Prezz. Cultural differences did not enter their ongoing competition as an issue. Instead, their rivalry revolved around awards, titles and victories in local and international competitions, coloured by jealousy and prestige. The ethics of such rivalry are concerned with honesty, originality, respect, attitude as well as breakdance knowledge, such as specific steps and their names, the history of breakdance and hip hop and the rules of the breakdance challenge. Most of the issues at stake between the two crews were grounded in the wider question of authenticity: the limits of commerciality of 'breaking' culture as well as where 'real hip hop' or 'real breaking' starts and ends. Similar disputes, challenges and confrontations were developed among different collectivities and individuals in the hip hop dance scene, concerning what kind of dance styles constitute a 'real' hip hop dance. House dance and waacking ${ }^{2}$, for example, are often attacked as not being part of hip hop but belonging main- ly to lyrical hip hop and street jazz. Struggles over power and hierarchy are very common within teams, concerning prestige and other issues, as mentioned above. For certain crews, it is very difficult to stick together for a long period of time. The game of power revolves around constructing, preserving and deconstructing already founded and identifiable ideas as well as reinventing new categories that deal with gender and ethical issues. However, there are clear distinctions between all-immigrant and predominantly Greek crews. Similarly, the setup divisions between b-girl and b-boy 'battles' reveal something concrete about the hegemonic realities of the Greek breakdance community.
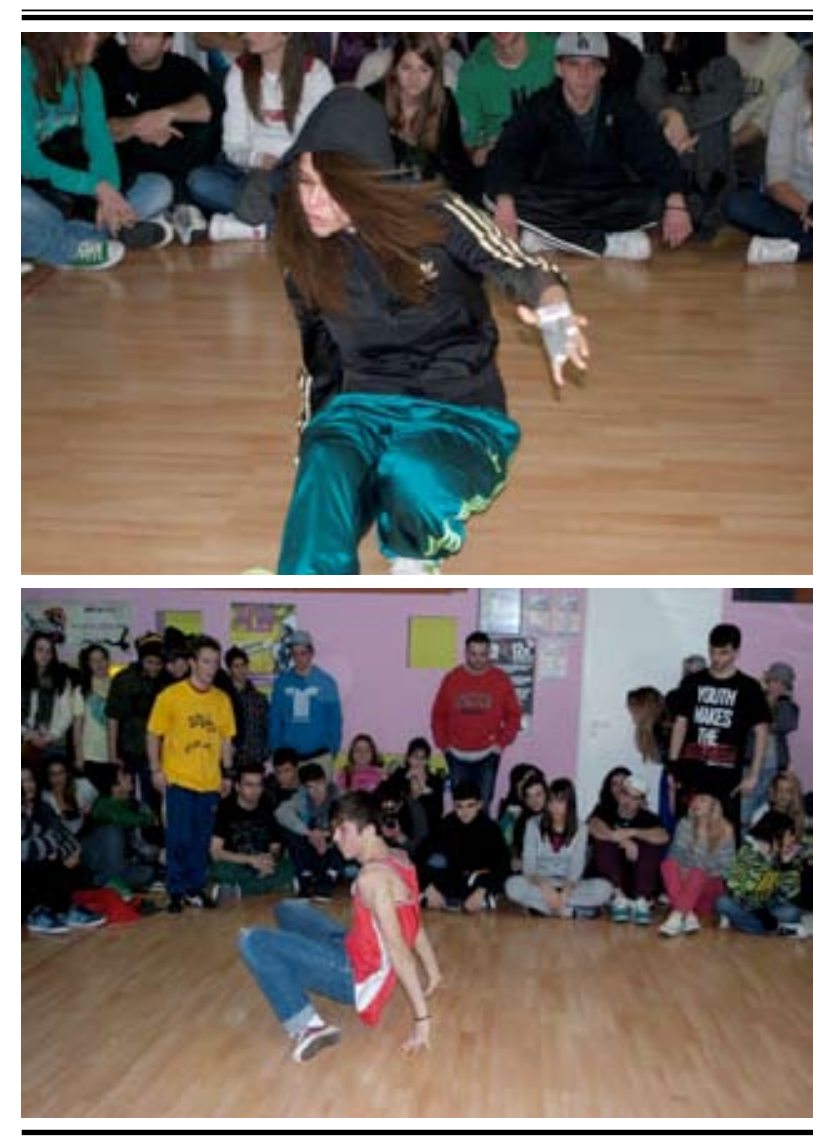

There are important qualities for the b-boys and b-girls. These relate to ways of dancing and the use of specific movements, as well as the general ethics of the culture they belong to. Thus, much importance is given to originality of movement and style, and accordingly to the individuality of the dancer. Breakers must avoid 'biting', that is stealing movements from others. Dancing should also be performed with 'a soul', 'a heart' and 'a spirit', and breakers should be 'real' and honest with themselves and others. 
One goal of the breaker is to 'give and take respect' from others. Respect is a very serious issue, as it could potentially affect the reputation of breakers throughout their entire life and career. These qualities are also visualized and expressed through movement, not only as people dance but also during everyday communication and comportment. Verbal expressions are also used to articulate value judgments. For example, when someone 'breaks it', it means that one achieves a high quality of dance performance 'on the beat', considered a compliment for most breakers.

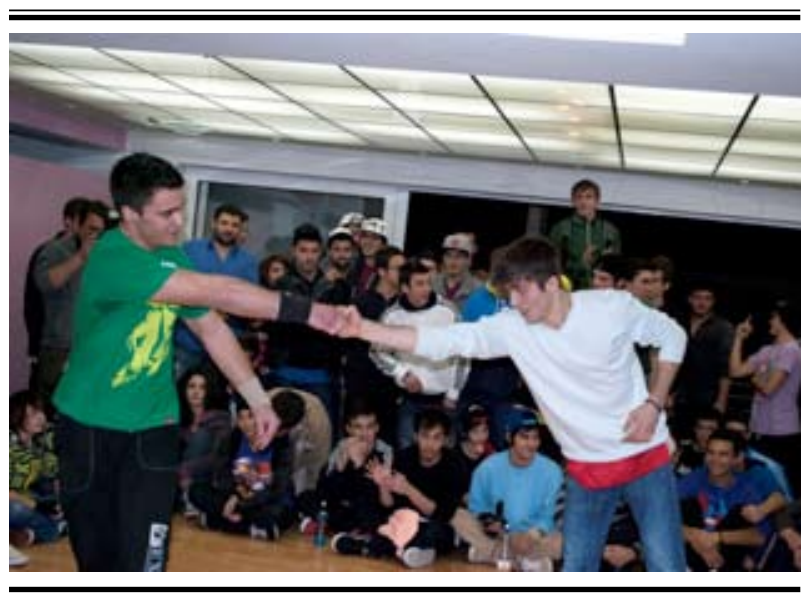

As previously mentioned there is also a powerful discourse within the breakdance community regarding 'real hip hop' and 'real breaking'. It is obvious that originality and authenticity play a fundamental role here. Some breakers focus on the underground aspects of breaking culture and are wary of its manipulation by the media and the market. Others, however, participate more in the popular entertainment industry and believe that 'breaking' should be promoted through TV shows and commercial events, because they perceive hip hop and the market as being interdependent. As members of the Dead Prezz crew claim: 'there is nothing wrong with making money out of it'. In view of all this it is apparent that the constant debates and arguments among the protagonists of hip hop dance styles have a highly significant relationship to an anti-mainstream discourse, predisposing the subject to act in ways so as to gain 'subcultural capital' (Thornton 1995: 11). This process is embraced by some and ignored by others.

Hip hop is promoted in Greece as well as worldwide as a vivid part of popular culture, and coexists with indigenous and local meanings of 'the popular'. The latest trend in mainstream night clubs of Athens is the mixing of popular Greek music with songs which include rapping in the delivery of lyrics. In music videos the influences from street dances - mainly new style and waacking - are obvious. In 2011 rapping and breakdance movements were included in Greece's performance at the Eurovision contest next to a popular Greek song and a folk dance called zeibekiko ${ }^{3}$. The inclusion of rapping in Greek popular music is a relatively recent phenomenon but has progressed with great success.
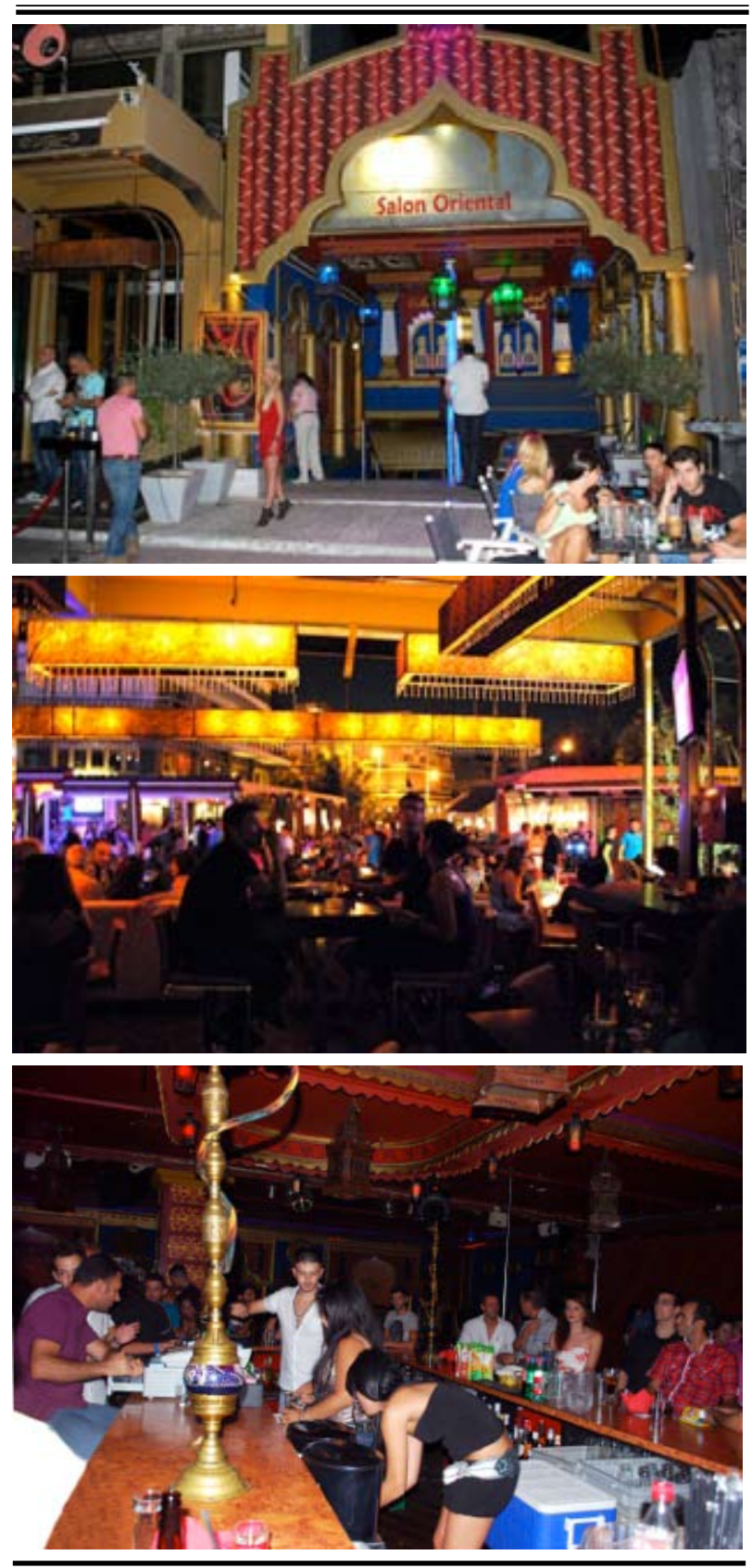

\section{'ELLINADIKA'}

Many of the Greek popular songs heard in night clubs in Bournazi - an area of Peristeri, a 
western suburb of Athens - adopt hip hop and RnB idioms. Night clubs, such as ellinadika ${ }^{4}$ use a combination of foreign pop and Greek songs, $\mathrm{RnB}$, as well as oriental music. The famous 'Greek night' encapsulates emotional structures which are connected to 'forbidden love', 'sin' (Economou 2005), passion and pain (ponos). These are distinctive affective qualities objectified and embodied within a framework of evening entertainment. Greek popular songs are replete with lyrics which refer to emotional pain and the burning of the 'heart' (kapsoura), and to crazy, mad love (trela) of a man for a woman - or vice versa. Dancing and singing the lyrics of these songs is very popular among people who go clubbing in Bournazi. By dancing or singing the lyrics, the heterosexual erotic play is projected, somatized and ritualized through the situational, ephemeral and imaginary identification with the heroes in the songs.

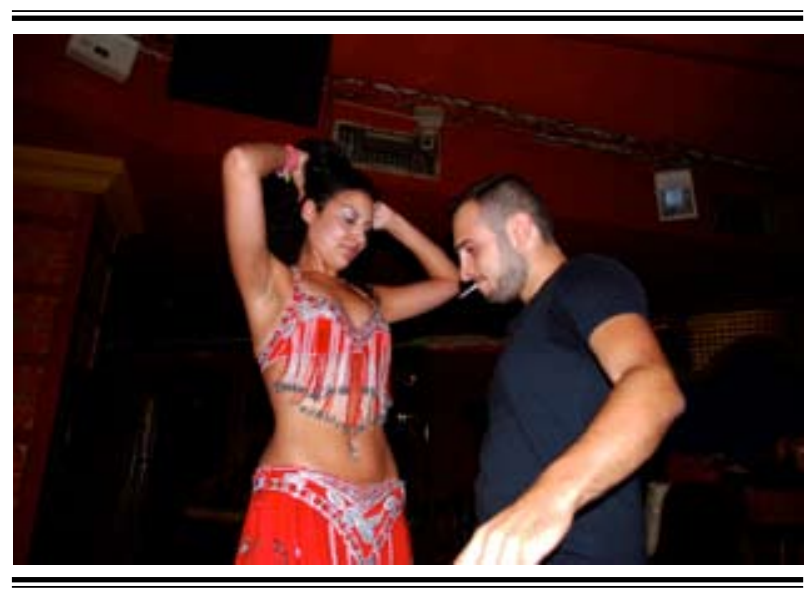

Both males and females usually dance 'tsifteteli', a kind of belly dance - sometimes on the bar or on a table - and they normally perform this dance in couples while the rest of the group sing to each other and clap their hands, yelling encouraging exclamations such as opa, dose (give) or pame (lets go) ${ }^{6}$. With the phrase 'break it', night clubbers invite the person who is dancing to set himself/herself out of control and exceed his/her ordinary limits. In the past, breaking plates used to be very popular in night clubs featuring live Greek popular music, called pistes (dance floors). In such popular entertainment contexts, conspicuous consumption is indicative of power while erotic and gender relations are related to practices of publicly showing off money on part of the male subject.
Materialistic narratives such as 'whoever has the money counts' circulate in contradiction to other narratives concentrating on emotions and the power of the 'heart'. These narratives and their expression through singing, dancing and drinking both articulate and challenge gender relations. The perceived ambiguity of certain performances, such as females dancing on the bar, may be seen both as a process of contestation as well as reinforcement of established notions of femininity. For example, the idea of the woman dancing 'for herself' on the bar and not for a certain male, or the stereotype of a woman who is 'crazy' and 'burns the man', may disturb settled phallocentric notions of women as quiet and obedient. Simultaneously, it also confirms a regulatory discourse of an individualistic culture that promotes and embraces in certain ways an out-of-limit, dangerous woman, both praised and feared by men.

In this night culture, clubbers perform their acts in a continuous, unconscious effort to verify or attain their authenticity. As players in a game, they strive to be 'real' and accuse as inauthentic those who pretend to be different from who they really are. The term laikos that is used to describe these groups means popular but also folk. Its roots go back to the underground folk music of the 1920's and 1950's, when bouzouki was the key instrument of rebetiko ${ }^{7}$ music and culture. Laiko takes various local meanings which are central to the cultures and people to which it refers. It is often used by outsiders to describe night clubbers and is connected to characteristics of honesty, simplicity, originality and a 'real self': a 'real man' or a 'real woman'8. Someone who is truly laikos, is someone who has 'a heart' and is real to himself and others. Being real is expressed through dancing, singing, flirting, chatting and drinking. Eroticism, but not romanticism, is intense in all these performances. A truly laiko male person must also be able to make it on his own and not depend on others for financial or other support. Individualism is a particularly strong element. By contrast, in 'breaking' team spirit is much more significant than the individual ego. 


\section{CONCLUSION}

These two cultures of entertainment constitute parallel realities intertwined with the concepts of authenticity and the 'popular'. 'Breaking' verifies Tricia Rose's argument that 'hip hop remains a never ending battle for status, prestige and group adoration which is always in formation, always contested and never fully achieved' (1994: 79). Similarly, an equally competitive and confrontational character is clearly identified in the mainstream night clubbing practices in ellinadika with a greater emphasis on egocentrism and conspicuous consumption. The subject in this context regresses and recoils between materialistic, individualistic and emotional paradigms in its effort to disentangle the world. In both cases, the element of authenticity is always present, playing a crucial role in the formation and negotiation of people's identities.

Thus, popular entertainment and its expressions as symbolic and cultural capital consist of common traits and affects which are embedded in the ethics, language and convictions of people who embrace them. Even though the ideals of these popular forms seem very different at first glance, authenticity is a central value at the points where variations of the 'popular' intersect. The 'popular', then, constitutes a shifting area that finds diverse expressions. There is great potential within popular entertainment for the reinvention of individual and social identities. In Greece, due to contemporary adverse sociopolitical circumstances, the study of popular entertainment forms is crucial for our understanding of processes of identity formation, vis-à-vis collapsing and dysfunctional formal institutions and social values. Therefore, it would be interesting to observe the negotiation of Greek identity as it unfolds into the future. As Stromberg points out: 'entertainment is so central in our culture that it eludes us' (2009: 20). Popular entertainment, though often intangible, can reveal gaps and connections between past and present circumstances. 佔

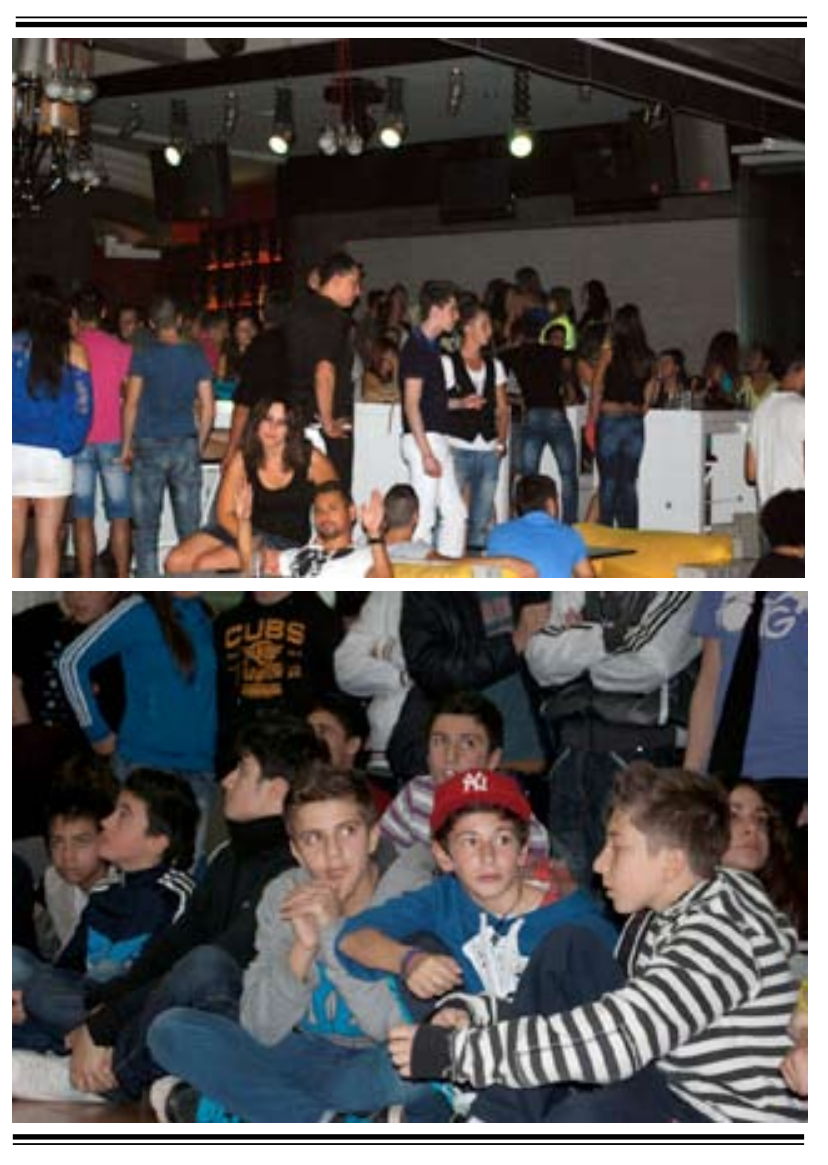

\section{ABOUT THE AUTHOR}

Natalia Koutsougera is an active social researcher and a Ph.D. candidate at Panteion University of Social and Political Sciences in Athens, Greece. Her doctoral thesis is about night clubbing and youth in the working class suburb of Peristeri, Western Attica. She has coproduced a 10 minute video on street and hip hop dance styles in Greece (www.dancetheater.gr) and an ethnographic film on 'breaking' (breakdance), under the title 'Born to Break'. 
1 Most breakers claim that breakdance is a media term and as such it is not authentic. They prefer the terms 'breakin' or 'break'.

2 The vast majority of house dance movements stem from Jazz, African, Latin, Soul and Hip hop and is an amalgamation of post-disco era. Waacking is a dance style that originated from the disco era of the 1970s clubbing scene in Los Angeles.

3 Zeibekiko is a Greek men's dance, danced publicly 'for oneself' and a performance of the 'inner self' (Cowan 1990).

4 'Ellinadiko' which means 'Greek club', is a kind of club that developed in the mid-1990s using both popular Greek and mainstream foreign music.

5 They are called kapsourotragouda, that is songs for the burning heart. According to Ampatzi, the notion of kapsoura refers to a particular kind of love, usually the one that is 'unfulfilled, oneway and non-mutual' (2009: 221).

6 In 'breaking' there are similar exclamations during battles, such as 'give energy' (dose energia).

7 Rebetiko is conceptualized as a kind of popular and folk Greek music subculture of 1920's and a kind of hybrid as it concentrates elements from the Byzantium, Ottoman Empire and Arabia. It was familiarized by "lower" social categories in post war Greece (Economou 2005).

8 'Laikos' also takes some negative connotations from those who do not embrace this kind of lifestyle. However, most of the night clubbers in Bournazi are proudly self-defined as laika pedia (laika kids).
Ampatzi, L. (2009) Drink for "Parea”: Sexual Entertainment in Contemporary Greece. Athens: Kedros.

Bourdieu, P. (1979) Distinction: A Social Critique Of The Judgment of Taste. London: Routledge.

Chang, J. (2005) Can't Stop Won't Stop: A History of the Hip Hop Generation. New York: St Martin Press.

Cowan, J. (1990) Dance and the Body Politic in Northern Greece. Princeton: Princeton University Press.

Economou, L. (2005) 'Rebetika, Laika and Skiladika: Limits and Relocations in the Perception of popular music of the 20th Century'. Pp 361-398 in N. Theotokas, N. Kotaridis and P. Lekkas (eds.) Dokimes: A Revue on Social Sciences. Athens: E.T. Consultance.

Rose, T. (1994) 'A style Nobody Can Deal With: Politics, Style and the Postindustrial City in Hip hop'. Pp 71-88, in A .Ross \& T. Rose (eds.) Microphone Fiends: Youth Music and Youth Culture. New York \& London: Routledge.

Stromberg, P. (2009) Caught in Play: How Entertainment Works on You. California: Stanford University Press.

Thornton, S. (1995). Club Cultures: Music, Media and Subcultural Capital. Cambridge: Polity Press.

\section{ACKNOWLEDGEMENTS}

I wish to thank Spyros Sifakakis, Evangelos Chrysagis, Leandros Kyriakopoulos and Stammis Chris for their fruitful and constructive comments and remarks. I would also want to thank my sister, Tatiana Koutsougera, for the inspiring photographs capturing moments of street and hip hop dance cultures and night clubbing. 